\title{
How do healthcare professionals manage ethical challenges regarding information in healthcare professional/patient clinical interactions? A review of concept- or argument-based articles and case analyses
}

\author{
C Ewuoso, ${ }^{1} \mathrm{MSC}, \mathrm{MA} ; \mathbf{S}$ Hall, ${ }^{1} \mathrm{PhD} ; \mathbf{K}$ Dierickx, ${ }^{2} \mathrm{PhD}$ \\ ${ }^{1}$ Centre for Applied Ethics, Department of Philosophy, Faculty of Arts and Social Sciences, Stellenbosch University, Cape Town, South Africa \\ ${ }^{2}$ Centre for Biomedical Ethics and Law, Department of Public Health and Primary Care, Faculty of Medicine, KU Leuven, Belgium
}

Corresponding author: C Ewuoso (19667876@sun.ac.za)

\begin{abstract}
Background. This study forms part of an ongoing research project that seeks to enhance the information-management skills of health professionals within the clinical context.

Objectives. To review case analyses and reviews and argument-based articles that use evidence and facts to prove whether or not a thesis is true. Specifically, this study attempts to provide a comprehensive overview of how health professionals manage information and related ethical challenges within the clinical context.

Method. We carried out a literature search in PubMed and PhilPapers, using two search strings. All searches generated 954 hits. After screenings for year of publication, language, title and abstracts, duplicates and full-text reading, three more articles were identified following a system update in PubMed. A total of 53 articles were finally included for review. We used the Q-sort technique for the analysis of identified articles.

Results. This review of concept- or argument-based articles and case analyses shows that there are five broad types of challenges communication related, confidentiality related, professional-duty related, value-differences related and treatment-plan related; and four broad strategies - consultation, negotiating differences, using professional/prudential judgement and striving towards resolution - for managing these ethical challenges, in 21 fields of practice within the clinical context.

Conclusion. This study greatly complements efforts aimed at providing a comprehensive overview of how health professionals manage information and related ethical challenges within the clinical context. Specifically, this study has identified four broad suggested strategies which may be employed to address the different challenges that can act as obstacles to communication within the clinical context. Further research is, however, needed to study whether these suggested strategies would indeed enhance communication and fiduciary relations between health professionals and patients.
\end{abstract}

S Afr J Bioethics Law 2017;10(2):75-82. DOI:10.7196/SAJBL.2017.v10i2.610

This study is part of an ongoing project that is focused on enhancing health professionals' skills in managing the ethical challenges around information management in health professionalpatient consultative encounters. Information management, following Swaminath, ${ }^{[1]}$ is here taken to mean the power of a health professional to control the information that is disclosed to or withheld from patients. It is not always clear how information should be managed within the clinical context - for example, whether one should disclose or not disclose it, or whether one should tell the truth, or lie or conceal information. Certain guidelines, such as the Australian Code of Conduct for Doctors, ${ }^{[2,3]}$ generally require physicians, for example, to disclose full and accurate information that has significant welfare implications, whether health-related or psychological, to their patients. Such disclosure, it is believed, would greatly strengthen patients' autonomy and significantly enhance their informed decision-making capacity. This obligation is a matter of ethics and law.
Other guidelines, such as the Health Professions Council of South Africa's Guidelines for Good Practice in the Healthcare Professions (Booklet $4(3: 3))^{[4]}$ exist, which permit a physician to withhold information in circumstances where disclosure is medically contraindicated. Disclosure is medically contraindicated if it would cause a depressed patient, for example, to become actively suicidal, or compromise a patient's recovery process, for example, telling a hypertensive patient receiving critical care in an intensive-care unit that his/her spouse has just died.

Notwithstanding the above, certain clinical situations still exist - such as when information regarding misattributed paternity is accidentally discovered in a health professional-patient consultative encounter - where deciding what course of action to take (disclosure or non-disclosure) may prove extremely difficult. On the one hand, disclosure of misattributed paternity information when a patient has not requested such information (and where establishing paternity is not the purpose of the patient's clinical interaction with the 
physician) may be taken by the patient as a violation of his/her right not to know; on the other, non-disclosure could be taken as a violation of patient's right to know.

In our earlier systematic review of empirical studies, ${ }^{[5]}$ we discovered that healthcare professionals generally employ four broad strategies for managing four broad types of ethical challenges relating to information management. The four types of challenges are confidentiality related, communication related, professional-duty related and decision-making related. The challenge-management strategies are resolution, consultation, stalling and disclosure/ concealment.

To gain a more comprehensive understanding of how healthcare professionals manage ethical challenges regarding information, the broad types of challenges health professionals face within the clinical context and the strategies they employ to address those challenges, we decided to embark upon a review of concept- or argument-based articles and case reviews or analyses, leading to this second study. In other words, we believe that a review of such articles will increase our knowledge of how healthcare professionals manage ethical challenges regarding information within the clinical context.

In light of the above information, this present review is significantly different from the first study, in that the studies reviewed are different. However, the research questions are the same in both studies. As in our review of empirical studies, this present review is concerned with the research question: 'How do healthcare professionals manage ethical challenges regarding information in health professionalpatient clinical interactions?' The term 'health professional' is defined by the International Standard Classification of Occupations (ISCO) ${ }^{[6]}$ as including generalists and specialist practitioners, pharmacists, nurses and dentists. What types of ethical challenges regarding information do concept- or argument-based articles and case reviews or analyses report that clinicians face within the clinical context? How do these clinicians address these ethical issues? These are some of the specific questions which could be derived from the research question. We have not found any published systematic review of such articles that has considered the research question posed in this study. Therefore, it is safe to say that this is the first systematic review of concept- or argument-based articles and case analyses to consider this research question. The eligibility criteria are provided in the next section.

\section{Methods}

Searches were conducted in PubMed on 16 January 2017 and 23 January 2017 for concept- or argument-based articles, as well as case analyses, that focus on how healthcare professionals manage information and related ethical challenges within clinical context. Search strings - using a methodological approach for designing search strings and conducting a literature search developed by Pillastrini et al. ${ }^{[7]}$ - were developed for our search for relevant materials. This methodological approach involves: framing a research question; looking up Medical Subject Heading (MeSH) terms for the components which make up the research question; reading published literature for alternative terms; and finally, combining these $\mathrm{MeSH}$ terms with Boolean operators (AND, OR, and NOT) in a database to deliver powerful, precise and relevant articles. For example, when we looked up the MeSH terms for 'clinical challenge', we found terms such as 'ethical dilemma', 'moral conflicts' and 'truth-telling', among others. The MeSH terms, rather than the term 'challenge', were then used to develop the search strings. These search strings generated 830 hits. An additional search, using a broad search string, was conducted in PhilPapers on 7 February 2017, and generated 124 hits, making a total of 954 hits.

\section{Inclusion and exclusion criteria}

This study will focus exclusively on concept- or argument-based articles and case analyses or reviews. Only articles that studied any of the following were included: how health professionals manage information within any clinical context; the ethical challenges faced by health professionals around information management within any clinical context; and how these health professionals manage such challenges or ethical dilemmas within any clinical context. Excluded from this review were empirical studies, letters, reports, dissertations and guidelines.

Article selection was conducted by the first author and discussed with the co-authors to ensure consistency of selection criteria. Finally, the articles which met our selection criteria were pooled together in EndNote database (version X6; Thomson Reuters, Canada).

Articles were excluded after screening for: year of publication (we limited our search to articles published between 2004 and 2017), whereby 107 articles were excluded; an English language requirement (42 articles excluded); based on title and abstracts (628 articles excluded); duplication (42 articles excluded); upon reading the full text, 85 other articles were found to be irrelevant to our research aim, and thus excluded. A total of 50 articles were included for review after this process. Three more studies that met our criteria were further identified in PubMed following a system update, giving us a total of 53 studies that were finally included for review (Table 1 and Fig. 1).

\section{Data extraction process}

Articles included for review were conventionally analysed to extract data. Consistent with the previous systematic review of empirical studies ${ }^{[5]}$ this study used the $\mathrm{Q}$ methodological approach to conduct this review. The Q-sort technique is designed for qualitatively sorting a number of individual viewpoints into broader categories by identifying similarities. This approach can show how viewpoints or expressed opinions are interconnected or related. As Watts and Stenner ${ }^{[8]}$ have observed, this is primarily an exploratory technique. Its aim is not to prove hypotheses. It can, however, bring a sense of coherence to individual research questions that have many, potentially complex and socially contested, answers. In

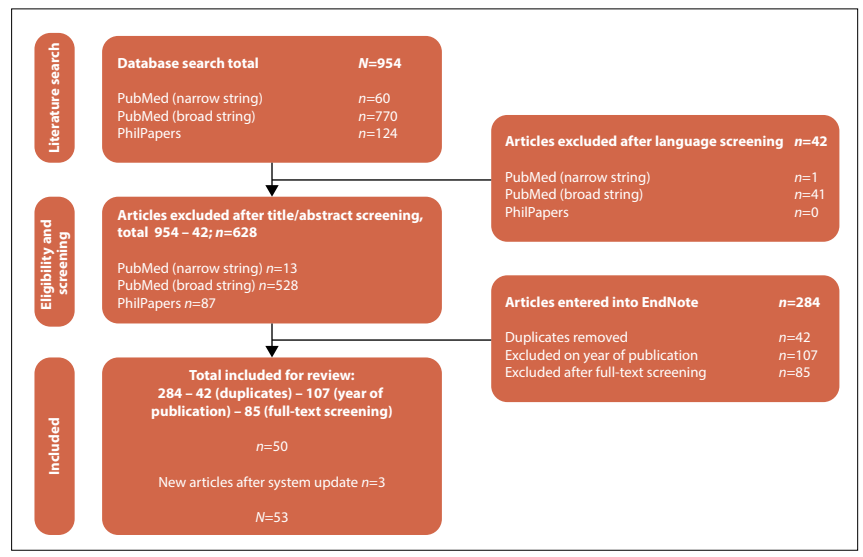

Fig. 1. Article selection process. 
Table 1. Literature search - search strings used to conduct searches for relevant articles in PubMed and PhilPapers

Search Date: 16 January 2017

Selected Restrictions: no restriction selected

Search Mode: Default mode: sort by relevance

Search String: ((((dilemma AND information)) AND (ethic OR ethics OR ethical OR moral)) AND (disclosure OR concealment OR "non disclosure" OR reporting OR returning OR "truth telling" OR recontacting OR withholding OR communicat*)) AND (intern OR surgeon OR nurse OR Allied Health Personnel OR caregiver OR dentist OR pharmacist OR geneticist OR "genetic counsellor" OR oncologist OR physician OR "general practitioner" OR "foreign medical graduate" OR resident OR anatomist OR psychiatrist OR "clinical scientist" OR GP)

Hits:60

\section{Database: PubMed}

Choose search number: Second search

\section{Search Date: 23 January 2017}

Selected Restrictions: no restriction selected

Search Mode: Default mode: sort by relevance

Search String: (((((ethic OR ethics OR ethical OR moral)) AND (clinic or clinical)) AND (dilemma OR complex* OR conflict)) AND (disclosure OR concealment OR "non disclosure" OR reporting OR returning OR recontacting OR withholding OR communicat*)) AND (intern OR surgeon OR nurse OR Allied Health Personnel OR caregiver OR dentist OR pharmacist OR geneticist OR "genetic counsellor" OR oncologist OR physician OR "general practitioner" OR "foreign medical graduate" OR resident $O R$ anatomist OR psychiatrist) Hits:770

\section{Database: PhilPapers}

Choose search number: Additional search

Search Date: 07 February 2017

Selected Restrictions: no restriction selected

Search Mode: Default mode: sort by relevance

Search String: "ethical dilemma" "healthcare professionals"; ethics "ethical dilemma" "Moral dilemma" dilemmas intern, surgeon, nurse, dentist, pharmacist, geneticist, oncologist, physician, psychiatrist

Hits:124

\section{Database: PubMed}

\section{Choose search number: Additional search for new articles due to system update}

Search Date: 02 September 2017

Selected Restrictions: no restriction selected

Search Mode: Default mode: sort by relevance

Search String: ((((dilemma AND information)) AND (ethic OR ethics OR ethical OR moral)) AND (disclosure OR concealment OR "non disclosure" OR reporting OR returning OR "truth telling" OR recontacting OR withholding OR communicat*)) AND (intern OR surgeon OR nurse OR Allied Health Personnel OR caregiver OR dentist OR pharmacist OR geneticist OR "genetic counsellor" OR oncologist OR physician OR "general practitioner" OR "foreign medical graduate" OR resident OR anatomist OR psychiatrist OR "clinical scientist" OR GP)

Hits: 3 new articles identified

summary, it is a useful technique for identifying common themes and sorting them into broad categories. Individual narratives may be used to supplement interpretation or understand the reason behind the sorted categories or themes. ${ }^{[8,9]}$ We adopted this methodological approach for its vertical and horizontal usefulness.

On the vertical line, it is a useful way for proceeding from a clearly defined research question to method, results and discussion. The research question plays a very important part in any $Q$ methodological study, since it dictates the nature and structure of the themes or categories to be generated. On the horizontal line, it is a good approach for generating broadly representative opinions or viewpoints expressed by the authors of the reviewed studies as to what constitute the ethical challenges regarding information in health professional-patient interactions.

This methodological approach was used in ATLAS.ti (Scientific Software Development $\mathrm{GmbH}$, Germany) to highlight the broad types of ethical challenges faced by health professionals within the clinical context, as well as strategies and approaches for managing them. We highly recommend ATLAS.ti for the careful qualitative analysis of texts and data. It is a useful tool for managing a large volume of data in creative, yet systematic ways. Our eligibility criteria have pooled 27 case analyses and reviews, and 26 concept- and argument-based articles, for this review (Table 2).

\section{Results \\ Challenges}

This review of concept- or argument-based articles, and case reviews or analyses, identified five principal challenges health professionals face within the clinical context. The challenges are communication related, confidentiality related, professional-duty related, valuedifferences related and treatment-plan related.

Some subthemes that emerged under communication-related challenges include questions as to what to disclose, and who should disclose it. ${ }^{[10-13]}$ For example, when incidental findings are discovered, the reviewed studies show that professionals often struggle with questions about how much should be disclosed (all incidental findings, only information with personal significance, only incidental findings with clinical significance, etc.), whether relatives should be contacted, especially if the condition is hereditary, and who should disclose the incidental information - the ordering physician or the geneticist.

Some ethical difficulties associated with professional-related challenges include dilemmas about revealing a colleague's error, telling the truth about an error made, and blurred, dual or conflicting relationship with patients. In the military, for example, mentalhealthcare professionals sometimes serve as consultants to military commanders as well as providers to individual patients. Occasionally, 
Table 2. General characteristics of studies reviewed

\begin{tabular}{|c|c|c|c|}
\hline Author & Year & Type of study & Journal \\
\hline Agyapong et al. ${ }^{[38]}$ & 2009 & Case review/analysis & J Forensic Legal Med \\
\hline Bahal et al. ${ }^{[48]}$ & 2010 & Case review/analysis & Int J Surgery \\
\hline Bell et al. ${ }^{[45]}$ & 2015 & Case review/analysis & Pediatrics \\
\hline Beng $^{[44]}$ & 2006 & Case review/analysis & Malays Fam Physician \\
\hline Chan Smutko et al..$^{[28]}$ & 2008 & Case review/analysis & Oncologist \\
\hline Cohen et al..$^{[55]}$ & 2012 & Case review/analysis & J Med Ethics \\
\hline Faith and Chidwick ${ }^{[42]}$ & 2009 & Case review/analysis & Crit Care Nurs \\
\hline Fine et al. ${ }^{[20]}$ & 2005 & Case review/analysis & Pediatrics \\
\hline Gupta et al..$^{[60]}$ & 2008 & Case review/analysis & J Dev Behav Pediatr \\
\hline Hatano et al. ${ }^{[52]}$ & 2011 & Case review/analysis & J Pain Symptom Manage \\
\hline Hyde et al. ${ }^{[43]}$ & 2013 & Case review/analysis & Dimensions Crit Care Nurs \\
\hline Johnson et al. ${ }^{[14]}$ & 2006 & Case review/analysis & Mil Med \\
\hline Kasman $^{[34]}$ & 2004 & Case review/analysis & J Gen Intern Med \\
\hline Lohiya $^{[37]}$ & 2013 & Case review/analysis & J Am Coll Dent \\
\hline Mueller et al..$^{[22]}$ & 2004 & Case review/analysis & Mayo Clin Proc \\
\hline Offit et al. ${ }^{[29]}$ & 2004 & Case review/analysis & JAMA \\
\hline Olsen $^{[51]}$ & 2010 & Case review/analysis & Am J Nurs \\
\hline Reynolds et al. ${ }^{[23]}$ & 2007 & Case review/analysis & Surg Clin N Am \\
\hline Rinehart $^{[56]}$ & 2013 & Case review/analysis & Clin Jam Soc Nephrol \\
\hline Schneider et al. ${ }^{[30]}$ & 2006 & Case review/analysis & J Genet Couns \\
\hline Tully et al. ${ }^{[19]}$ & 2016 & Case review/analysis & AMA J Ethics \\
\hline Umeorah and Chukwuneke ${ }^{[31]}$ & 2013 & Case review/analysis & Ann Med Health Sci Res \\
\hline Westra et al. ${ }^{[35]}$ & 2009 & Case review/analysis & Eur J Pediatr \\
\hline White and Lofwall[57] & 2015 & Case review/analysis & J Psychiatr Res \\
\hline Youngner $^{[24]}$ & 2016 & Case review/analysis & AMA J Ethics \\
\hline Kadooka et al. ${ }^{[26]}$ & 2016 & Case review/analysis & Bioethics \\
\hline Ercan Avci ${ }^{[12]}$ & 2017 & Case review/analysis & Med Health Care Philos \\
\hline Battistuzzi et al. ${ }^{[27]}$ & 2012 & Concept/argument-based article & Clin Genet \\
\hline Becker et al..$^{[10]}$ & 2015 & Concept/argument-based article & J Pain Symptom Manage \\
\hline Brown $^{[62]}$ & 2010 & Concept/argument-based article & Pediatr Radiol \\
\hline Brown et al..$^{[59]}$ & 2016 & Concept/argument-based article & Clin J Am Soc Nephrol \\
\hline Coggon and Wheeler ${ }^{[54]}$ & 2010 & Concept/argument-based article & Ann R Coll Surg Engl \\
\hline Daugherty $^{[11]}$ & 2004 & Concept/argument-based article & Cancer Invest \\
\hline Ganai $^{[15]}$ & 2014 & Concept/argument-based article & World J Surg \\
\hline Gold $^{[58]}$ & 2004 & Concept/argument-based article & Intern Med J \\
\hline Gutman $^{[25]}$ & 2005 & Concept/argument-based article & J Deaf Stud Deaf Educ \\
\hline Kipnis $^{[39]}$ & 2006 & Concept/argument-based article & Am J Bioethics \\
\hline Lee $^{[21]}$ & 2005 & Concept/argument-based article & Thorac Surg Clin \\
\hline Lucast $^{[61]}$ & 2007 & Concept/argument-based article & Bioethics \\
\hline Magnavita and Bergamaschi ${ }^{[32]}$ & 2009 & Concept/argument-based article & Radiol Med \\
\hline Magnavita et al. ${ }^{[46]}$ & 2009 & Concept/argument-based article & Radiol Med \\
\hline McGowan $^{[53]}$ & 2012 & Concept/argument-based article & Crit Care Nurs \\
\hline McNamee et al..$^{[16]}$ & 2016 & Concept/argument-based article & Clin Sports Med \\
\hline Miller et al. ${ }^{[49]}$ & 2014 & Concept/argument-based article & World J Surg \\
\hline Monaghan and Begley ${ }^{[50]}$ & 2004 & Concept/argument-based article & J Clin Nurs \\
\hline Lzaro-Muoz $^{[13]}$ & 2014 & Concept/argument-based article & J Law Med Ethics \\
\hline Partridge $\mathrm{e}^{[17]}$ & 2014 & Concept/argument-based article & J Bioeth Inq \\
\hline Petrik et al. ${ }^{[47]}$ & 2015 & Concept/argument-based article & J Psychiatr Pract \\
\hline Purdy and Wadhwani[40] & 2006 & Concept/argument-based article & Neonatal Netw \\
\hline Rentmeester ${ }^{[41]}$ & 2013 & Concept/argument-based article & Hum Vaccin Immunother \\
\hline Surbone $e^{[33]}$ & 2008 & Concept/argument-based article & Support Care Cancer \\
\hline Turillazzi and Neri ${ }^{[18]}$ & 2014 & Concept/argument-based article & BMC Med Ethics \\
\hline Ying $^{[36]}$ & 2014 & Concept/argument-based article & World J Surg \\
\hline
\end{tabular}


these providers are asked to provide reports on patients who are being assessed for promotion; providing such a report may lead to these professionals shifting from a clinical to an evaluative role in relation to these patients. ${ }^{[14-18]}$ Some examples of treatment-planrelated challenges include: difficulties in getting patients and/or their family to appreciate the futility of treatment, and to prepare for death; conflicts between the physician's expert opinion and family wishes regarding treatment; ethical difficulties with regard to going ahead with an urgent and lifesaving treatment plan when a patient is undecided or cannot make up his/her mind in time to accept a lifesaving organ transplant, ${ }^{[19-24]}$ and conflicts between patient wishes and the physician's opinion regarding treatment. As these reviewed studies have shown, dealing with an undecided patient can be an ethical nightmare for emergency- and intensive-care unit health professionals, since this often stalls required treatments or leads to communication breakdown. ${ }^{[19]}$

Confidentiality-related challenges generally relate to ethical difficulties with managing information of significant health or personal value; difficulties with regard to keeping patient information private, for example, in a closely knit community such as the Deaf community, where information spreads quickly; ${ }^{[25]}$ and dilemmas regarding the breaching of confidential information in order to benefit third or at-risk parties. ${ }^{[26-31]}$

Finally, regarding challenges arising from differences in values, one frequently occurring issue is the limit of the current medical-ethics framework, specifically principlism, to manage culturally or religiously nuanced clinical contexts, or clinical contexts where physicians and patients are motivated by different religious or cultural values. ${ }^{[32-36]}$

\section{Fields of practice}

This review identifies 21 fields of practice within the clinical context where concept- and argument-based articles and case reviews have examined the challenges described in the preceding section. These fields of practice are: audiology, burn/accident unit, cardiology, dentistry, palliative/oncology, general surgery, genetics, geriatrics, haematology, intensive-care unit, mental healthcare, neonatology, nephrology, nursing, obstetrics/gynaecology, paediatrics, radiology, sports medicine, thoracic, trauma/emergency unit and vaccinology.

The reviewed studies reveal that struggling to decide whether to honour a patient's request not to report abuse is a common ethical conundrum for dentists, ${ }^{[3]]}$ mental-healthcare professionals, ${ }^{[38]}$ and paediatricians. ${ }^{[39]}$ In these instances, this dilemma presents a conflict between a professional's duty to report abuse, and their respect for a patient's autonomous decision. In regions or countries where protective agencies are inept and overworked and foster care is dangerous or unavailable, reporting child abuse, as Kipnis ${ }^{[39]}$ has pointed out, may be more difficult for a paediatrician, since such a report is more likely to result in termination of therapy and further injury to the child than protection and care.

Our review equally shows that neonatal staff also experience dilemmas that they perceive as bordering on child abuse, such as when parents decide to ignore best medical recommendations against initiating aggressive care for an infant with a poor prognosis. ${ }^{[40]}$ In neonatology, conflicts between a physician's expert opinion and parental or family wishes regarding treatment, leading to communication breakdown, appear to be a constant source of ethical difficulties for health professionals. ${ }^{[4]]}$

Finally, in intensive-care units, some reviewed studies ${ }^{[19,42,43]}$ identified difficulties in getting family members to appreciate the futility of treatment, and going ahead with treatment plans when the patient is ambivalent or indecisive, as two common challenges faced by professionals within this clinical context.

\section{Emotions experienced}

Studies report that some of the emotions professionals experience when they encounter these ethical challenges are anger, anxiety, frustration, exhaustion, depression, devastation, distress and guilt, to mention but a few, which could lead to burnout. ${ }^{[42,44,45]}$

\section{Strategies for managing these challenges}

Four themes for dealing with ethical difficulties regarding information emerged in this review: consultation; negotiating differences; using professional/prudential judgement; and trying to find resolution.

\section{Consultation}

Consultation is the most widely suggested strategy for managing information and related ethical challenges. This strategy was suggested by the reviewed studies for managing challenges relating to confidentiality, professional duty, value differences, treatment plans and communication-related challenges.

Consultation includes seeking the professional advice of colleagues within or outside the field of practice, consulting an ethics committee/group, and consulting with team members. For example, oncologists, intensivists, paediatricians and nurses who face the ethical difficulties of communicating the futility of treatment to patients or family members, or with whom patients or family members have a disagreement over treatment plans, are encouraged to consult with their experienced colleagues within or outside of the hospital. It is believed that these experienced colleagues can provide useful insights for professionals who struggle with the above ethical difficulties. ${ }^{[25,34,47-50]}$

\section{Negotiating differences}

Negotiating differences involves engaging in active dialogue with patients and family members to reach common ground when there is a difference of opinion, or holding a discussion with team members with whom there is disagreement over a treatment plan.

The negotiation of differences is suggested for resolving disagreements between professionals and patients or family members, such as when parents do not consent to disclosing information to their sick child, or when professionals and patients are motivated by different values. This strategy is also suggested for resolving conflicts between a professional's opinion and patient or family wishes regarding treatment. For example, when family members cannot agree about whether to withdraw life support, or when family members or proxies hold contrary views regarding the withdrawal of treatment, nurses and intensivists are encouraged to negotiate these differences through active dialogue with the family members or proxies..$^{[33,43,51-56]}$ In addition, when patients cannot make up their minds to consent to urgent lifesaving surgery, White 
and Lofwall ${ }^{[57]}$ found that surgeons find it useful to encourage such patients to discuss their medical options (treatments) with close relatives, since this often leads to situations where patients eventually accept evidence-based treatment(s).

\section{Using professional/prudential judgement}

Professional judgement involves the use of discretion to filter (non-) disclosure according to the cultural or religious practices of patients and/or family members, since insensitivity to the patient's values can lead to the provision of information to someone who is not ready to receive it, causing distress for him/her. ${ }^{[58]}$

This is a commonly suggested strategy for clinical situations where patients and professionals are motivated by different values; it can also be used to manage information when a patient is incapacited. For example, when family members - but not legal proxies - request a patient's confidential information, and the patient is incapacitated, some studies ${ }^{[42,43]}$ suggest that critical-care nurses and/or mentalhealthcare professionals should carefully judge whether disclosure conforms with prevailing regulations or with the patient's advance directives (if any). The latter is important especially if the patient, before incapacitation, indicated that he/she did not want his/her family to know anything about his/her medical information.

Additionally, in regions where non-disclosure of life-threatening conditions is acceptable, or where patients - owing to cultural or religious influences - consider it a taboo to talk about death, reviewed studies ${ }^{[12,33,59]}$ also suggest that professionals would be ethically correct to filter disclosure according to the cultural beliefs and practices of patients or family, provided that the decision not to disclose information does not in any way jeopardise the treatment of patients or their best interests. ${ }^{[60]}$

\section{Resolution}

Finding resolution may involve: deferring decision-making to independent experts when there is a conflict or a blurred/dual relationship with patients; seeking legal advice, waivers or court orders when patients do not consent to providing their health information to parties who may be at risk of infectious diseases or preventable/ manageable health conditions; referring patients to another hospital when differences in a professional's values and the patient's cultural beliefs cannot be resolved; and finally, having a discussion prior to diagnosis or treatment to elicit the patient's wishes.

For example, radiologists, nephrologists (within the context of organ transplantation) and geneticists who frequently face the challenge of managing incidental information are encouraged to hold a discussion with the patient at the onset of the clinical relationship to elicit their wishes and preferences regarding (non-)disclosure of such information. ${ }^{[12,61,62]}$ If the patient's preferences were not elicited before the start of the clinical relationship, and the sociocultural codes of the society indicate that the foreseen (serious) risks are likely to occur, Avci ${ }^{[12]}$ considers that nephrologists who accidentally discover information about misattributed paternity during a human leukocyte antigens (HLA)-typing test are justified in taking a paternalistic decision not to disclose. In addition, military psychologists or psychiatrists who often engage patients in many different contexts and roles (as military colleagues and as patients) are urged to avoid conflicts of duties by referring patients or colleagues to independent experts who might be able to offer appropriate care. ${ }^{[14]}$
The reviewed studies also show that general surgeons and mentalhealth professionals can seek legal advice or a court order to breach confidential information to benefit at-risk parties. ${ }^{[38,39]}$

\section{Discussion}

In the previous section, the presentation of our findings was weighted towards some of the 21 fields of practice listed. It is not practically possible to discuss the ethical challenges experienced in each of the 21 fields of practice. We lack the space for such an overwhelming endeavour. The inability to present all the ethical challenges experienced by professionals in each of the 21 fields of practice, as reported by the reviewed studies, is one limitation of this study.

This discussion is also not an attempt to discuss the ethical challenges in each of the 21 fields. Notwithstanding, our research question will set the tone of this discussion: 'How do healthcare professionals manage ethical challenges regarding information within the clinical context?' Other questions which arise from this research question are: 'What types of ethical challenges regarding information do concept articles, argument-based articles and case analyses report that clinicians face within the clinical context?' and 'How do these clinicians address these ethical issues?' Therefore, we shall focus on these ethical challenges in general.

This review shows that there are five broad types of challenge: communication related, confidentiality related, professional-duty related, value-differences related and treatment plan-related, and four broad strategies (consultation, negotiating differences, using professional/prudential judgement and trying to find resolution) for managing information and related ethical challenges in the 21 fields of practice within the clinical context.

New themes and categorisations emerged from this review. Challenges relating to value differences and treatment plans were grouped as subcategories of those relating to decision-making in our review of empirical studies, while negotiating differences and using professional/prudential judgement are entirely new themes that were not present in the review of empirical studies.

These new themes and categorisations are the result of our methodological approach - the use of Q-sort techniques that derive themes and codes from texts. In our review of empirical studies, ${ }^{[5]}$ professionals described challenges relating to value differences and treatment plans as ethical dilemmas that often frustrate their decision-making process, and they were categorised as decisionmaking-related challenges in the review of empirical studies. However, in this present review, challenges relating to value differences and treatment plans are discussed - in addition to those related to communication, professional duties and confidentiality - as ethical dilemmas that often lead to communication breakdown amongst professionals or between professionals and patients.

This communication breakdown (and how to forestall it) is the theme that underlies all the five broad types of challenges identified in this present review. Information and communication are intrinsically linked. Information is expressed or managed within the context of communication. Therefore, good communication is key to patient care - a breakdown in communication could jeopardise it. It may lead to the provision of information to a patient who is neither ready nor sufficiently prepared to receive such information, resulting in significant distress. 
We define communication broadly in this study. It encompasses the content of the communication, the necessary communication skills, and the judgement required to determine when communication is appropriate. In order to prevent significant distress to patients, there is a need to enhance communication between health professionals and their patients, thereby preventing a breakdown of the same within the clinical context. In this regard, this study reaches the same conclusions as those of empirical studies conducted by Lotz et al., ${ }^{\left[{ }^{[3]}\right.}$ Williams et al. ${ }^{[64]}$ and Helft et al. ${ }^{[65]}$

Some proposals for enhancing communication within the clinical context have been made. Ghazal et al., ${ }^{[66]}$ for example, proposed the 'MORAL' method - massaging dilemmas; outlining options; reviewing criteria and resolving; affirming positions and acting; and finally, looking back. However, recent studies such as that of Brown et al. ${ }^{[59]}$ have concluded that these proposed frameworks and guidelines for enhancing communication within the clinical context have mostly been developed around Anglo-American models of truth-telling and patient autonomy.

Many patients and families in certain regions such as Asia and Africa, Brown et al ${ }^{[59]}$ observe, make decisions using different models that current medical ethics frameworks have not accommodated. New frameworks that adequately accommodate models used by such patients and their families, or that take very seriously the genuine differences that often exist between professionals and patients, will contribute towards bridging this gap. Additionally, we recommend a comprehensive revision of medical-ethics curricula for students to accommodate other models of truth-telling. In the same vein, this study also recommends medical-ethics training and education for health professionals which focuses on a variety of models of communication and truth-telling.

In addition to the limitations already stated in this section, this study also has another limitation. We do observe that the tough screening process, as well as the rigorous eligibility criteria and developed search strings, may have resulted in the exclusion of potentially relevant materials. For example, we pooled articles only from studies published between 2004 and 2017; this resulted in the exclusion of potentially relevant articles published before 2004. Notwithstanding the limitations indicated in this section, this review of argumentbased articles and case analyses greatly complements our previous review of empirical studies. ${ }^{[5]}$ This study has increased our knowledge of how healthcare professionals manage ethical challenges regarding information within the clinical context. Future research studies can build on the outcome of this study by developing methods that will enhance communication in a variety of clinical contexts.

\section{Conclusion}

This review of argument-based articles and case analyses has identified five challenges, related to professional duty, confidentiality, communication, value differences and treatment plans that can act as obstacles to communication within the clinical context. It has also identified four broad (suggested) strategies for addressing these obstacles. They are consultation, negotiating differences, using professional/prudential judgement, and trying to find resolution.

Further research is, however, needed to study whether these suggested strategies will indeed enhance communication and fiduciary relations between health professionals and patients. Nonetheless, health professionals should be aware that a number of strategies exist that they can adopt to address the broad types of challenges identified around information management in a variety of clinical contexts.

Acknowledgements. The authors acknowledge and are profoundly grateful to the reviewers and journal editors for their useful, reflective and critical feedback.

Author contributions. CE and SH developed the project proposal upon which this study is based. CE and KD adapted a proposal for this particular study and developed the method section of this work. CE was responsible for selecting articles for review, but this was discussed extensively with $\mathrm{KD}$ to ensure consistency of inclusion and exclusion criteria. A second revision of the process was done by $\mathrm{SH}$ to ensure consistency with the selection criteria, as well as with the larger project aims and objectives. All authors critically revised this manuscript, raised no objections to its submission for publication, and are responsible for its intellectual content.

\section{Funding. None.}

Conflicts of interest. None.

1. Swaminath G. The doctor's dilemma: Truth telling. Indian J Psychiatry 2008;50(2):83-84. https://doi.org/10.4103/0019-5545.42392

2. Australian Medical Council. Good Medical Practice: A Code of Conduct for Doctors in Australia. Victoria: AMC, 2009. http://www.amc.org.au/joomla-files/ images/Final_Code.pdf (accessed 13 March 2015).

3. Gough IR. The significance of Good Medical Practice: a code of conduct for doctors in Australia. Med J Aust 2014;200(3):148-149.

4. Health Professions Council of South Africa Guidelines for Good Practice in Healthcare Profession. Pretoria: HPCSA. http://www.hpcsa.co.za/Uploads/editor/ UserFiles/downloads/ethical_rules/Booklet\%204\%20Informed\%20Consent\%20 September\%20\%202016.pdf (accessed 12 March 2017).

5. Ewuoso CO, Hall S, Kris, D. How Healthcare Professionals Manage Information and Challenges in the Clinical Context: A Review of Empirical Literature. Stellenbosch Centre for Applied Ethics, 2017.

6. International Labour Organization. International Standard Classification of Occupations. Geneva: ILO, 2012. http://www.ilo.org/wcmsp5/groups/public/--dgreports/---dcomm/---publ/documents/publication/wcms_172572.pdf (accessed 4 December 2017).

7. Pillastrini P, Vanti C, Curti S, et al. Using PubMed search strings for efficient retrieval of manual therapy research literature. J Manip Physiol Ther 2015:38(2):159-166. http:s//doi.org/10.1016/j.jmpt.2014.11.005

8. Watts S, Stenner P. Doing Q methodology: Theory, method and interpretation Qual Res Psychol 2005;2(1):67-91. https://doi.org/10.1191/1478088705qp022oa

9. Roberts JK, Hargett CW, Nagler A, et al. Exploring student preferences with a Q-sort: The development of an individualised renal physiology curriculum. Adv Physiol Educ 2015;39(3):149-157. https://doi.org/10.1152/advan.00028.2015

10. Becker G, Jors K, Block S. Discovering the truth beyond the truth. J Pain Symptom Manage 2015;49(3):646-649. https://doi.org/10.1016/j.jpainsymman.2014.10.016

11. Daugherty CK. Examining ethical dilemmas as obstacles to hospice and palliative care for advanced cancer patients. Cancer Invest 2004;22(1):123-131. https://doi. org/10.1081/cnv-120027587

12. Avci E. Should physicians tell the truth without taking social complications into account? A striking case. Med Health Care Philos 2017;7(5):7500. https://doi. org/10.1007/s11019-017-9779-9

13. Lzaro-Muoz G. The fiduciary relationship model for managing clinical genomic incidental findings. J Law Med Ethics 2014;42(4):576-589. https://doi.org/ 10.1111/jlme.12177

14. Johnson WB, Bacho R, Heim M, et al. Multiple-role dilemmas for military mental healthcare providers. Mil Med 2006;171(4):311-315. https://doi.org/10.7205/ milmed.171.4.311

15. Ganai S. Disclosure of surgeon experience. World J Surg 2014;38(7):1622-1625. https://doi.org/10.1007/s00268-014-2558-3

16. McNamee MJ, Partridge B, Anderson L. Concussion ethics and sports medicine. Clin Sports Med 2016;35(2):257-267. https://doi.org/10.1016/j.csm.2015.10.008

17. Partridge B. Dazed and confused: Sports medicine, conflicts of interest, and concussion management. J Bioeth Inq 2014;11(1):65-74. https://doi.org/10.1007/ s11673-013-9491-2

18. Turillazzi E, Neri M. Medical error disclosure: From the therapeutic alliance to risk management: The vision of the new Italian code of medical ethics. BMC Med Ethics 2014;15(1):57. https://doi.org/10.1186/1472-6939-15-57 
19. Tully AA, Diaz GC, Renz JF. Should physicians attempt to persuade a patient to accept a compromised organ for transplant? AMA J Ethics 2016;18(2):101-107. https://doi.org/10.1001/journalofethics.2016.18.2.ecas1-1602

20. Fine RL, Whitfield JM, Carr BL, et al. Medical futility in the neonatal intensive care unit: Hope for a resolution. Pediatrics 2005;116(5):1219-1222. https://doi. org/10.1542/peds.2004-2790

21. Lee KF. Postoperative futile care: Stopping the train when the family says keep going. Thoracic Surg Clin 2005:15(4):481-491. https://doi.org/10.1016/j. thorsurg.2005.06.005

22. Mueller PS, Hook CC, Fleming KC. Ethical issues in geriatrics: A guide for clinicians. Mayo Clin Proc 2004:79(4):554-562. https://doi.org/10.4065/79.4.554

23. Reynolds $S$, Cooper $A B$, McKneally $M$. Withdrawing life-sustaining treatment Ethical considerations. Thoracic Surg Clin 2005;15(4):469-480. https://doi. org/10.1016/j.thorsurg.2005.06.002

24. Youngner SJ. How to communicate clearly about brain death and first-person consent to donate. AMA J Ethics 2016;18(2):108-114. https://doi.org/10.1001/jour nalofethics.2016.18.2.ecas2-1602

25. Gutman V. Ethical reasoning and mental health services with deaf clients. J Deaf Stud Deaf Educ 2005;10(2):171-183. https://doi.org/10.1093/deafed/eni017

26. Kadooka Y, Okita T, Asai A. Ethical obligations in the face of dilemmas concerning patient privacy and public interests: The Sasebo schoolgirl murder case. Bioethics 2016:30(7):520-527. https://doi.org/10.1111/bioe.12249

27. Battistuzzi L, Ciliberti R, Forzano F, de Stefano F. Regulating the communication of genetic risk information: The Italian legal approach to questions of confidentiality and disclosure. Clin Genet 2012;82(3):205-209. https://doi.org/10.1111 /j.1399-0004.2012.01935

28. Chan-Smutko G, Patel D, Shannon KM, et al. Professional challenges in cance genetic testing: Who is the patient? Oncologist 2008;13(3):232-238. https://doi. org/10.1634/theoncologist.2007-0203

29. Offit K, Groeger E, Turner S, et al. The duty to warn a patient's family members about hereditary disease risks. JAMA 2004;292(12):1469-1473. https://doi. org/10.1001/jama.292.12.146

30. Schneider KA, Chittenden AB, Branda KJ, et al. Ethical issues in cancer genetics: 1) Whose information is it? J Genet Couns 2006;15(6):491-503. https://doi. org/10.1007/s10897-006-9053-4

31. Umeora O, Chukwuneke F. Ethical dilemma and management of infertility in HIV seropositive discordant couples: A case study in Nigeria. Ann Med Health Sci Res 2013;3(1):99-101. https://doi.org/10.4103/2141-9248.109460

32. Magnavita N, Bergamaschi A. Ethical problems in radiology: Radiological consumerism. Radiol Med 2009;114(7):1173-1181. https://doi.org/10.1007/ s11547-009-0438-y

33. Surbone A. Cultural aspects of communication in cancer care. Recent Results Cancer Res 2006;168:91-104

34. Kasman DL. When is medical treatment futile? A guide for students, residents and physicians. J Gen Intern Med 2004;19(10):1053-1056. https://doi.org/10.1111/ j.1525-1497.2004.40134.x

35. Westra AE, Willems DL, Smit BJ. Communicating with Muslim parents: 'The four principles' are not as culturally neutral as suggested. Eur J Pediat 2009:168(11):1383-1387. https://doi.org/10.1007/s00431-009-0970-8

36. Ying I. Withholding tragic knowledge may lead to a tragic death: A palliative care perspective. World J Surg 2014;38(12):3290-3291. https://doi.org/10.1007/ s00268-014-2676-y

37. Lohiya S. Domestic violence dilemma in the dental clinic. J Am Coll Dent 2013;80(3):9-11.

38. Agyapong VI, Kirrane R, Bangaru R. Medical confidentiality versus disclosure: Ethical and legal dilemmas. J Forensic Leg Med 2009;16(2):93-96. https://doi. org/10.1016/j.jflm.2008.08.007

39. Kipnis K. A defense of unqualified medical confidentiality. Am J Bioeth 2006;6(2):7 18. https://doi.org/10.1080/15265160500506308

40. Purdy IB, Wadhwani RT. Embracing bioethics in neonatal intensive care, part II: Case histories in neonatal ethics. Neonatal Netw 2006;25(1):43-53. https://doi. org/10.1891/0730-0832.25.1.43

41. Rentmeester CA. Professionalism, fidelity and relationship-preservation: Navigating disagreement and frustration in clinical encounters. Hum Vaccin Immunother 2013;9(8):1812-1814. https://doi.org/10.4161/hv.24432

42. Faith $\mathrm{K}$, Chidwick $P$. Role of clinical ethicists in making decisions about levels of care in the intensive care unit. Crit Care Nurse 2009;29(2):77-84. https://doi. org/10.4037/ccn2009285

43. Hyde YM, Kautz DD, Jordan M. What to do when the family cannot agree to withdraw life support. Dimens Crit Care Nurs 2013:32(6):276-279. https://doi. org/10.1097/DCC.0000000000000001
44. Beng KS. Collusion in palliative care. Malays Fam Physician 2006;1(2-3):62-64.

45. Bell SK, Mann KJ, Truog R, et al. Should we tell parents when we've made an error? Pediatrics 2015;135(1):159-163. https://doi.org/10.1542/peds.2014-0293

46. Magnavita N, Magnavita G, Fileni A, et al. Ethical problems in radiology: Medical error and disclosure. Radiol Med 2009;114(8):1345-1355. https://doi.org/10.1007/ s11547-009-0445-z

47. Petrik ML, Billera M, Kaplan $Y$, et al. Balancing patient care and confidentiality: Considerations in obtaining collateral information. Journal Psychiatr Pract 2015;21(3):220-224. https://doi.org/10.1097/PRA.0000000000000072

48. Bahal N, Papanikitas A, Sokol DK. A bleeding controversy: Duties and decisions in the face of conflicting advice. Int J Surg 2010;8(1):32-34. https://doi. org/10.1097/10.1016/j.ijsu.2009.10.002

49. Miller ME, Siegler M, Angelos P. Ethical issues in surgical innovation. World J Surg 2014;38(7):1638-1643. https://doi.org/10.1097/10.1007/s00268-014-2568-1

50. Monaghan C, Begley A. Dementia diagnosis and disclosure: A dilemma in practice. J Clin Nurs 2004;13(3a):22-29. https://doi.org/10.1097/10.1111/j.13652702.2004.00922.x

51. Olsen DP. Want to achieve the 'greatest good'? Listen to your patients. Am J Nurs 2010;110(2):66-67. https://doi.org/10.1097/01.NAJ.0000368065.85297.2b

52. Hatano Y, Yamada M, Fukui K. Shades of truth: Cultural and psychological factors affecting communication in pediatric palliative care. J Pain Symptom Manage 2011;41(2):491-495. https://doi.org/10.1097/10.1016/j.jpainsymman.2010.12.002

53. McGowan C. Patients' confidentiality. Crit Care Nurs 2012;32(5):61-64. https://doi. org/10.1097/10.4037/ccn2012135

54. Coggon J, Wheeler R. Confidence and conflicts of duty in surgery. Ann Royal Coll Surg Engl 2010;92(2):113-117. https://doi.org/10.1097/10.1308/00358841 0X12628812458932

55. Cohen LL, Stolerman M, Walsh C, et al. Challenges of genetic testing in adolescents with cardiac arrhythmia syndromes. J Med Ethics 2012;38(3):163-167. https://doi. org/10.1097/10.1136/medethics-2011-100087

56. Rinehart A. Beyond the futility argument: The fair process approach and timelimited trials for managing dialysis conflict. Clin J Am Soc Nephrol 2013;8(11):2000 2006. https://doi.org/10.1097/10.2215/CJN.12191212

57. White MM, Lofwall MR. Challenges of the capacity evaluation for the consultation-liaison psychiatrist. J Psychiatr Pract 2015;21(2):160-170. https://doi org/10.1097/01.pra.0000462609.10101.2a

58. Gold M. Is honesty always the best policy? Ethical aspects of truth telling. Intern Med J 2004;34(9-10):578-580. https://doi.org/10.1111/j.1445-5994.2004.00673.x

59. Brown EA, Bekker HL, Davison SN, et al. Supportive care: Communication strategies to improve cultural competence in shared decision-making. Clin J Am Soc Nephrol 2016;11(10):1902-1908. https://doi.org/10.1097/10.2215/CJN.13661215

60. Gupta VB, Willert J, Pian M, et al. When disclosing a serious diagnosis to a minor conflicts with family values. J Dev Behav Pediatr 2008;29(3):231. https://doi. org/10.1097/DBP.0b013e31817996ab

61. Lucast EK. Informed consent and the misattributed paternity problem in genetic counseling. Bioethics 2007;21(1):41-50. https://doi.org/10.1097/10.1111/j.1467 8519.2007.00522.x

62. Brown SD. The intersection of ethics and communication in prenatal imaging: Challenges for the pediatric radiologist 2010;40(4):514-517. https://doi. org/10.1007/s00247-009-1516-y

63. Lotz JD, Jox RJ, Meurer C, et al. Medical indication regarding life-sustaining treatment for children: Focus groups with clinicians. Palliat Med 2016;30(10):960970. https://doi.org/10.1097/10.1177/0269216316628422

64. Williams C, Alderson P, Farsides B. Dilemmas encountered by health practitioners offering nuchal translucency screening: A qualitative case study. Prenat Diagn 2002;22(3):216-220. https://doi.org/10.1002/pd.289

65. Helft PR, Chamness A, Terry C, et al. Oncology nurses' attitudes toward prognosis-related communication: A pilot mailed survey of oncology nursing society members. Oncol Nurs Forum 2011;38(4):468-474. https://doi. org/10.1097/10.1188/11.ONF.468-474

66. Ghazal L, Saleem Z, Amlani G. A medical error: To disclose or not to disclose. Clin Res Bioethics 2014:5(2):1-3. https://doi.org/10.1097/doi:10.4172/2155 9627.1000174

Accepted 2 November 2017 